\title{
Presenilin E318G variant and Alzheimer's disease risk: the Cache County study
}

\author{
Ariel A. Hippen ${ }^{1}$, Mark T. W. Ebbert ${ }^{1}$, Maria C. Norton², JoAnn T. Tschanz ${ }^{2}$, Ronald G. Munger ${ }^{3}$, \\ Christopher D. Corcoran ${ }^{4}$ and John S. K. Kauwe ${ }^{1 *}$
}

\begin{abstract}
Background: Alzheimer's disease is the leading cause of dementia in the elderly and the third most common cause of death in the United States. A vast number of genes regulate Alzheimer's disease, including Presenilin 1 (PSEN1). Multiple studies have attempted to locate novel variants in the PSEN1 gene that affect Alzheimer's disease status. A recent study suggested that one of these variants, PSEN1 E318G (rs17125721), significantly affects Alzheimer's disease status in a large case-control dataset, particularly in connection with the APOEE4 allele.

Methods: Our study looks at the same variant in the Cache County Study on Memory and Aging, a large population-based dataset. We tested for association between E318G genotype and Alzheimer's disease status by running a series of Fisher's exact tests. We also performed logistic regression to test for an additive effect of E318G genotype on Alzheimer's disease status and for the existence of an interaction between E318G and APOEE4.

Results: In our Fisher's exact test, it appeared that APOE\&4 carriers with an E318G allele have slightly higher risk for AD than those without the allele (3.3 vs. 3.8); however, the $95 \%$ confidence intervals of those estimates overlapped completely, indicating non-significance. Our logistic regression model found a positive but non-significant main effect for E318G ( $p=0.895)$. The interaction term between E318G and APOEE4 was also non-significant $(p=0.689)$.

Conclusions: Our findings do not provide significant support for E318G as a risk factor for AD in APOEE4 carriers. Our calculations indicated that the overall sample used in the logistic regression models was adequately powered to detect the sort of effect sizes observed previously. However, the power analyses of our Fisher's exact tests indicate that our partitioned data was underpowered, particularly in regards to the low number of E318G carriers, both AD cases and controls, in the Cache county dataset. Thus, the differences in types of datasets used may help to explain the difference in effect magnitudes seen. Analyses in additional case-control datasets will be required to understand fully the effect of E318G on Alzheimer's disease status.
\end{abstract}

Keywords: Alzheimer's disease, Presenilin, Rare variants, Epistasis

\section{Background}

Alzheimer's disease (AD) is the most common type of dementia in the elderly and the third most common cause of death in the United States [1]. It is notoriously difficult to diagnose, with highly variable clinical symptoms and no existing laboratory test able to detect it conclusively [2]. The two primary markers of AD, amyloid plaques and neurofibrillary tangles, can usually only be detected at autopsy.

\footnotetext{
* Correspondence: kauwe@byu.edu

'Department of Biology, Brigham Young University, Provo, UT, USA

Full list of author information is available at the end of the article
}

AD's clinical complexity is compounded by its complex etiology, and a vast number of genes have been implicated [3, 4]. Ridge et. al. recently estimated that $33 \%$ of $\mathrm{AD}$ phenotypic variation can be explained by genetic mutations, and suggested that $25 \%$ of the total variation may be explained by currently-unknown rare mutations [5]. Ebbert et. al. further demonstrated that epistasis plays a critical role in Alzheimer's and may explain a significant proportion of the missing heritability [6]. The Presenilin 1 gene (PSEN1) is one of the genes known to affect Alzheimer's disease risk [7]; it codes for a transmembrane protein that forms the core of the gamma secretase complex, an enzyme 
that cleaves amyloid precursor protein into $\beta$ amyloid peptides [8]. PSEN1 mutations have been shown to affect amyloid precursor protein cleavage, resulting in amyloid $\beta-42$ peptides. These longer, more hydrophobic fragments tend to form into plaques that are associated with damaged brain tissue, making amyloid $\beta-42$ levels an important pathological marker for AD [9].

Another relevant biomarker in pre-symptomatic Alzheimer's is the tau protein, which is responsible for stabilizing microtubules in the brain. However, phosphorylated tau (ptau) is less able to perform this function, allowing the microtubules to become disorganized and form neurofibrillary tangles [10]. An increased phosphorylation of tau has been associated with increased amyloid deposition into plaques [11]. Fagan et. al. observed that the ratio of amyloid $\beta-42$ to ptau is associated with cognitive decline [12] and thus the two combined could make a probable biomarker for preclinical Alzheimer's disease.

Multiple studies have identified novel variants in the PSEN1 gene that affect Alzheimer's disease status [1315]. A recent study by Benitez et. al. found that one such mutation, PSEN1 E318G (rs17125721), increases the ratio of tau to $A \beta-42$ and ptau to $A \beta-42$ in the cerebrospinal fluid; as discussed previously, these ratios can be an important indicator of a preclinical AD phenotype [16]. The Benitez et. al. study also suggests a potential gene-gene interaction between PSEN1 and APOE. Specifically, it suggests that $E 318 G$ carriers who are also heterozygous carriers of the $A P O E \varepsilon 4$ allele have a similar $\mathrm{AD}$ risk as individuals who are homozygous for $A P O E \varepsilon 4$ and twice the risk of those heterozygous for $A P O E \varepsilon 4$ without the E318G allele.

Gene-gene interactions are an important element of AD etiology [17-20], and an interaction between PSEN1 E318G and APOE could have an important function in the genetic pathways of the disease, but the existence of such an effect has not yet been validated in other datasets. Here, we attempt to replicate the effects of E318G in connection to $A P O E$ on Alzheimer's status in a population-based dataset.

\section{Methods}

Samples for this study came from the Cache County Study on Memory Health and Aging. When the study began in 1994, the 5092 subjects therein represented approximately $90 \%$ of all residents age 65 and older in Cache County, Utah. Case-control status was determined through a series of clinical dementia evaluations and cognitive assessments, including the Modified MiniMental State Exam-Revised [21]. These assessments were administered every three years over a period of twelve years. Cases were defined as those subjects meeting criteria determined by the National Institute of Neurological Disorders and Stroke-Alzheimer's disease and Related Disorders Association to indicate possible or probable AD. Individuals with dementia only showed symptoms of late-onset $\mathrm{AD}$ with no other comorbid forms of dementia. Cognitively normal individuals were free of any symptoms of $\mathrm{AD}$ and other comorbid forms of dementia at all stages of screening. There were no early-onset Alzheimer's cases in the dataset. Additional information about data collection and phenotype determination has been reported previously [22].

We genotyped the PSEN1 E318G locus (rs17125721) for 3420 individuals using a custom TaqMan assay. Genotypes were called based on cluster analyses using the default settings in the TaqMan genotyper software (Thermo Fisher). The marker had a call rate of greater than $98 \%$. Of the 3420 individuals, 478 were clinically ascertained Alzheimer's disease cases and 2942 were cognitively normal controls.

We excluded all individuals for whom $A P O E$ and E318G genotyping or Alzheimer's disease case/control status were unavailable. We used Fisher's exact test to calculate odds ratios for effect of $A P O E \varepsilon 4$ status on $\mathrm{AD}$ risk in E318G carriers and E318G non-carriers. To determine if the effect of $E 318 G$ on AD risk was different for $A P O E \varepsilon 4$ homozygotes versus heterozygotes we calculated the odds ratios for each combination of E318G carrier/non-carrier status and their number of $A P O E \varepsilon 4$ alleles $(0,1$ or 2$)$.

We used the odds ratios described above to calculate the synergy factor between E318G status and $A P O E \varepsilon 4$ status. Synergy factors are the ratio of the observed and expected odds ratios for the two interacting SNPs. Assuming there is no synergy between the SNPs (i.e., the SNPs are independent); the expected odds ratio then equals the product of the individual odds ratios. The synergy factor is calculated by dividing the observed odds ratio by the expected odds ratio for the interacting SNPs. A synergy factor that deviates from 1 suggests a statistical interaction between the SNPs [19],[20]. We calculated the synergy factor of $E 318 G$ and $A P O E \varepsilon 4$ to test further the existence of an interaction between these SNPs and their effect on Alzheimer's disease risk.

We ran a logistic regression model using case/control status as the response, with E318G, age, gender, and $A P O E \varepsilon 4$ positive or negative status as covariates. We also included an interaction between $A P O E$ and E318G to test the finding by Benitez et. al. that carriers of both E318G and APOE\&4 were more at risk of developing AD than carriers of either mutation alone. We then tested the E318G mutation's effect on AD status independent of $A P O E \varepsilon 4$ in a second logistic regression model by using only $A P O E \varepsilon 3$ homozygotes in the Cache County 
Table 1 Results from Fisher's exact test. The odds ratio for Alzheimer's Disease risk for individuals who were carriers of E318G and APOE\&4 was higher than the odds ratio for those who only carried APOEع4, but the confidence intervals overlap

\begin{tabular}{|c|c|c|c|c|c|c|}
\hline \multicolumn{7}{|c|}{ Alzheimer's risk based on E318G status and APOEع4 Status } \\
\hline Strata & & Cases & Controls & $P$ value & OR (95 \% Cl) & Power \\
\hline \multirow[t]{2}{*}{ E318G + } & APOE $\varepsilon 4(+)$ & 8 & 20 & 0.0172 & $3.8(1.1-13.3)$ & 0.66 \\
\hline & APOE $\varepsilon 4(-)$ & 8 & 77 & & & \\
\hline \multirow[t]{2}{*}{$\mathrm{E} 318 \mathrm{G}-$} & $\mathrm{APOE} \varepsilon 4(+)$ & 253 & 765 & $<2.2 \times 10^{-16}$ & $3.3(2.7-4.0)$ & 1.0 \\
\hline & $\mathrm{APOE} \varepsilon 4(-)$ & 209 & 2080 & & & \\
\hline
\end{tabular}

dataset $(n=1916)$. In this model, we included E318G, age, and gender as covariates.

To determine if we had sufficient statistical power to observe an effect of E318G on AD status in connection to $A P O E \varepsilon 4$, we calculated the minimum discernible effect size of E318G in all individuals in the Cache County Study using a power analysis [23]. We used sample size, E318G exposure, and $\mathrm{AD}$ status to find the smallest effect size we could detect with $80 \%$ power. If we had sufficient power to detect the kind of odds ratios that were found by Benitez et. al., then we could be confident that our sample size was large enough to discover the same effect if it existed in the Cache County dataset. Then, to determine if we had enough power to see an effect of E318G on AD status independent of $A P O E \varepsilon 4$, we calculated the minimum discernible effect size of E318G in APOE\&3 homozygotes.

\section{Results}

It would appear that $A P O E \varepsilon 4$ carriers with an E318G allele have slightly higher risk for AD than those without the allele (3.3 vs. 3.8); however, the $95 \%$ confidence intervals of these two estimates overlap completely (Table 1). Similarly, comparisons of odds ratios for AD risk based on E318G and number of $A P O E \varepsilon 4$ alleles revealed that E318G carriers with one $A P O E \varepsilon 4$ allele were at a higher-but nonsignificant-risk for $\mathrm{AD}(\mathrm{OR}=3.5, \mathrm{CI}=1.0-12.7, p=0.043)$ compared to $A P O E \varepsilon 4$ heterozygotes who did not carry the E318G allele $\left(\mathrm{OR}=3.0, \mathrm{CI}=2.4-3.7, p<2.2 \times 10^{-16}\right)$. E318G carriers with two APOE\&4 alleles had a larger odds ratio $(\mathrm{OR}=9.1, \mathrm{CI}=0.1-759.3, p=0.197)$ than noncarriers $(\mathrm{OR}=7.5, \mathrm{CI}=4.6-12.0, p=2.4 \times 10-15)$, but the confidence interval was extremely large and the result was not significant (Table 2). Based on our synergy factor calculation, the odds ratios obtained from the Fisher's exact test comparing Alzheimer's disease risk based on APOE\&4 presence or absence did not give evidence of a significant interaction between E318G and APOE\&4 (Synergy factor = 1.17, $p=0.78)$.

In our first logistic regression model, which considered all individuals in the dataset and included an interaction term between $A P O E \varepsilon 4$ and $E 318 G$, we found a positive but non-significant main effect for E318G $(p=0.895)$. The interaction term between E318G and APOE\&4 was also non-significant $(p=0.689)$. The second logistic regression model, which included only those who were homozygous for the non-disease-causing APOE\&3 allele, also did not have a significant additive effect for $E 318 G$ $(p=0.826)$. Our power analysis indicated that, with a sample size of 3420 , we had $80 \%$ power to detect an odds ratio of 1.9 or bigger if one existed (alpha $=0.05$ ). For the second logistic regression model, with a sample size of 1916 APOE 83 heterozygotes, we had $80 \%$ power to detect an odds ratio of 2.4 or larger (alpha $=0.05$ ).

\section{Discussion}

We failed to detect significant associations with E318G and $\mathrm{AD}$ as described by Benitez et al. While the direction of our results are consistent with those reported by Benitez et al., our results provide little support that the E318G allele increases risk for $\mathrm{AD}$ in APOE\&4 carriers (Tables 1 and 2). Further studies will be necessary to clarify the effects of E318G on AD. The lack of replication in rare variant

Table 2 Results from Fisher's exact test. The odds ratios observed were higher for E318G+ individuals than E318G- individuals with the same number of APOE\&4 alleles, but the $95 \%$ confidence intervals for these groups overlap

\begin{tabular}{|c|c|c|c|c|c|c|}
\hline \multicolumn{7}{|c|}{ Alzheimer's risk based on E318G status and number of APOE\&4 Alleles } \\
\hline Strata & & Cases & Controls & $P$ value & OR $(95 \% \mathrm{Cl})$ & Power \\
\hline \multirow[t]{3}{*}{$\overline{\mathrm{E} 318 \mathrm{G}+}$} & APOE $\varepsilon 44$ & 1 & 1 & 0.197 & $9.1(0.1-759.3)$ & 0.04 \\
\hline & APOEE4 (+) & 7 & 19 & 0.043 & $3.5(1.0-12.7)$ & 0.16 \\
\hline & APOE\&4 (-) & 8 & 77 & & & \\
\hline \multirow[t]{3}{*}{ E318G - } & APOE\&44 & 36 & 48 & $2.4 \times 10^{-15}$ & $7.5(4.6-12.0)$ & 1.0 \\
\hline & $\mathrm{APOE} \varepsilon 4(+)$ & 217 & 717 & $<2.2 \times 10^{-16}$ & $3.0(2.4-3.7)$ & 1.0 \\
\hline & APOE\&4 (-) & 209 & 2080 & & & \\
\hline
\end{tabular}


associations and with interactions can be difficult to interpret, as these associations are particularly sensitive to genetic and phenotypic heterogeneity. While our calculations indicate the overall sample is adequately powered to detect the sort of effect sizes observed by Benitez et al., the power analyses of our Fisher's exact tests indicate that our study of the partitioned data was underpowered, particularly in regards to the low number of E318G carriers, both $\mathrm{AD}$ cases and controls, in the Cache county dataset. Differences in ascertainment and population may have presented challenges for replication in the Cache County Study of the finding of Benitez et al. As such, we believe that further analyses using samples that are more similar to those used in the original report will be necessary to determine the significance of the interaction between the APOE\&4 allele and E318G on Alzheimer's disease risk.

\section{Conclusions}

Rare variants play a significant role in Alzheimer's disease phenotypic variance. The number of possible variants with a functional effect, as well as the existence of epistatic interactions, means that many further studies will be required to fully characterize rare variants' roles. Our study did not find any evidence of PSEN1 E318G having a significant effect on Alzheimer's disease status, but it is possible that significance could be found using larger, case-control datasets. More studies involving greater number of rare variants, examined both independently and in combination, will help to make the genetic etiology of Alzheimer's disease clearer and more clinically actionable.

\section{Acknowledgments \\ This work was supported by grants from NIH (R01AG11380, R01AG21136, R01AG31272, R01AG042611). The authors thank the participants and staff of the Dementia Progression Study, the Utah Population Database, and the Cache County Study on Memory Health and Aging for their important contributions to this work. The funders had no role in study design, data collection and analysis, decision to publish, or preparation of the manuscript.}

\section{Declarations}

Publication of this article was funded by Brigham Young University's Department of Biology.

This article has been published as part of BMC Genomics Volume 17 Supplement 3, 2016: Selected articles from the 12th Annual Biotechnology and Bioinformatics Symposium: genomics. The full contents of the supplement are available online at https://bmcgenomics.biomedcentral.com/ articles/supplements/volume-17-supplement-3.

\section{Availability of data and materials}

Researchers can apply for access to data from the Cache County Study at http://www.usu.edu/epicenter/htm/studies/memorystudy.

\section{Authors' contributions}

AAH assisted in project design, data analysis, and preparation of the manuscript. MTWE assisted in project design, data analysis, and preparation of the manuscript. MCN assisted in data collection and manuscript preparation. JTT assisted in data collection and manuscript preparation. RGM assisted in data collection and manuscript preparation. CDC assisted in data collection and manuscript preparation. JSKK assisted in data collection, project design, data analysis, and preparation of the manuscript. All authors read and approved the final manuscript.

\section{Competing interests}

The authors declare that they have no competing interests.

Consent for publication

Not applicable.

\section{Ethics approval and consent to participate}

All Cache County study procedures were approved by the Institutional Review Boards of Utah State, Duke and the Johns Hopkins University. All analyses in this study were approved by the Brigham Young University Institutional Review Board.

\section{Author details}

'Department of Biology, Brigham Young University, Provo, UT, USA ${ }^{2}$ Department of Psychology, Utah State University, Logan, UT, USA. ${ }^{3}$ Department of Nutrition, Dietetics, and Food Science, Utah State University, Logan, UT, USA. ${ }^{4}$ Department of Mathematics and Statistics, Utah State University, Logan, UT, USA.

Published: 29 June 2016

\section{References}

1. James $B D$, Leurgans $S E$, Hebert LE, Scherr PA, Yaffe K, Bennett DA. Contribution of Alzheimer disease to mortality in the United States. Neurology. 2014;82:1045-50

2. McKhann G, Drachman D, Folstein M, Katzman R, Price D, Stadlan EM. Clinical diagnosis of Alzheimer's disease: report of the NINCDS-ADRDA Work Group under the auspices of Department of Health and Human Services Task Force on Alzheimer's Disease. Neurology. 1984;34:939-44.

3. Lambert JC, Ibrahim-Verbaas CA, Harold D, Naj AC, Sims R, Bellenguez C, DeStafano AL, Bis JC, Beecham GW, Grenier-Boley B, Russo G, Thorton-Wells TA, Jones N, Smith AV, Chouraki V, Thomas C, Ikram MA, Zelenika D, Vardarajan BN, Kamatani Y, Lin CF, Gerrish A, Schmidt H, Kunkle B, Dunstan ML, Ruiz A, Bihoreau MT, Choi SH, Reitz C, Pasquier F, et al. Meta-analysis of 74,046 individuals identifies 11 new susceptibility loci for Alzheimer's disease. Nat Genet. 2013:45:1452-8.

4. Strittmatter WJ, Saunders AM, Schmechel D, Pericak-Vance M, Enghild J, Salvesen GS, Roses AD. Apolipoprotein E: high-avidity binding to betaamyloid and increased frequency of type 4 allele in late-onset familial Alzheimer disease. Proc Natl Acad Sci U S A. 1993;90:1977-81.

5. Ridge PG, Mukherjee S, Crane PK, Kauwe JSK, Alzheimer's Disease Genetics Consortium. Alzheimer's disease: analyzing the missing heritability. PLoS One. 2013;8:e79771.

6. Ebbert MTW, Ridge PG, Kauwe JSK. Bridging the gap between statistical and biological epistasis in Alzheimer's disease. BioMed Res Int. 2015;2015:870123.

7. Chávez-Gutiérrez L, Bammens L, Benilova I, Vandersteen A, Benurwar M, Borgers M, Lismont S, Zhou L, Van Cleynenbreugel S, Esselmann H, Wiltfang J, Serneels L, Karran E, Gijsen H, Schymkowitz J, Rousseau F, Broersen K, De Strooper B. The mechanism of ${ }^{\gamma}$-Secretase dysfunction in familial Alzheimer disease. EMBO J. 2012;31:2261-74.

8. Sun L, Zhao L, Yang G, Yan C, Zhou R, Zhou X, Xie T, Zhao Y, Wu S, Li X, Shi Y. Structural basis of human $Y$-secretase assembly. Proc Natl Acad Sci U S A. 2015;112:6003-8.

9. Cacquevel M, Aeschbach L, Houacine J, Fraering PC. Alzheimer's diseaselinked mutations in presenilin-1 result in a drastic loss of activity in purified Y-secretase complexes. PLoS One. 2012;7:e35133.

10. Kolarova M, García-Sierra F, Bartos A, Ricny J, Ripova D. Structure and pathology of tau protein in Alzheimer disease. Int J Alzheimers Dis. 2012; 2012:731526.

11. Fagan AM, Mintun MA, Shah AR, Aldea P, Roe CM, Mach RH, Marcus D, Morris JC, Holtzman DM. Cerebrospinal fluid tau and ptau(181) increase with cortical amyloid deposition in cognitively normal individuals: implications for future clinical trials of Alzheimer's disease. EMBO Mol Med. 2009;1:371-80.

12. Fagan AM, Roe CM, Xiong C, Mintun MA, Morris JC, Holtzman DM. Cerebrospinal fluid tau/beta-amyloid(42) ratio as a prediction of cognitive decline in nondemented older adults. Arch Neurol. 2007;64:343-9.

13. Ishikawa A, Piao Y-S, Miyashita A, Kuwano R, Onodera O, Ohtake H,Suzuki M, Nishizawa M, Takahashi H. A mutant PSEN1 causes dementia with Lewy bodies and variant Alzheimer's disease. Ann Neurol. 2005;57:429-34. 
14. Cruchaga C, Haller G, Chakraverty S, Mayo K, Vallania FLM, Mitra RD, Faber K, Williamson J, Bird T, Diaz-Arrastia R, Foroud TM, Boeve BF, Graff-Radford NR, St Jean P, Lawson M, Ehm MG, Mayeux R, Goate AM, NIA-LOAD/NCRAD Family Study Consortium. Rare variants in APP, PSEN1 and PSEN2 increase risk for AD in late-onset Alzheimer's disease families. PLoS One. 2012;7 e31039.

15. Nygaard HB, Lippa CF, Mehdi D, Baehring JM. A Novel Presenilin 1 Mutation in Early-Onset Alzheimer's Disease With Prominent Frontal Features. Am J Alzheimers Dis Other Demen. 2014:29:433-5.

16. Benitez BA, Karch CM, Cai Y, Jin SC, Cooper B, Carrell D, Bertelsen S, Chibnik L, Schneider JA, Bennett DA, Alzheimer's Disease Neuroimaging Initiative (ADNI), Genetic and Environmental Risk for Alzheimer's Disease Consortium (GERAD1), Fagan AM, Holtzman D, Morris JC, Goate AM, Cruchaga C. The PSEN1, p.E318G Variant Increases the Risk of Alzheimer's Disease in APOE- $\varepsilon 4$ Carriers. PLoS Genet. 2013:9:e1003685.

17. Ebbert MTW, Ridge PG, Wilson AR, Sharp AR, Bailey M, Norton MC, Tschanz JT, Munger RG, Corcoran CD, Kauwe JSK. Population-based analysis of Alzheimer's disease risk alleles implicates genetic interactions. Biol Psychiatry. 2014;75:732-7.

18. Ebbert MTW, Boehme KL, Wadsworth ME, Staley LA, Alzheimer's Disease Neuroimaging Initiative, Alzheimer's Disease Genetics Consortium, Mukherjee $\mathrm{S}$, et al. Interaction between variants in CLU and MS4A4E modulates Alzheimer's disease risk. Alzheimers Dement J Alzheimers Assoc. 2015.

19. Cortina-Borja M, Smith AD, Combarros O, Lehmann DJ. The synergy factor: a statistic to measure interactions in complex diseases. BMC Res Notes. 2009;2:105.

20. Combarros O, Cortina-Borja M, Smith AD, Lehmann DJ. Epistasis in sporadic Alzheimer's disease. Neurobiol Aging. 2009;30:1333-49.

21. Tschanz JT, Welsh-Bohmer KA, Plassman BL, Norton MC, Wyse BW, Breitner JCS, Cache County Study Group. An adaptation of the modified minimental state examination: analysis of demographic influences and normative data: the cache county study. Neuropsychiatry Neuropsychol Behav Neurol. 2002;15:28-38.

22. Breitner JC, Wyse BW, Anthony JC, Welsh-Bohmer KA, Steffens DC, Norton MC, Tschanz JT, Plassman BL Meyer MR, Skoog I, Khachaturian A. APOE-epsilon4 count predicts age when prevalence of $A D$ increases, then declines: the Cache County Study. Neurology. 1999;53:321-31.

23. Demidenko E. Sample size determination for logistic regression revisited. Stat Med. 2007;26:3385-97.

\section{Submit your next manuscript to BioMed Central and we will help you at every step:}

- We accept pre-submission inquiries

- Our selector tool helps you to find the most relevant journal

- We provide round the clock customer support

- Convenient online submission

- Thorough peer review

- Inclusion in PubMed and all major indexing services

- Maximum visibility for your research

Submit your manuscript at www.biomedcentral.com/submit

) Biomed Central 